\title{
Effect of temperature-dependent surface heat transfer coefficient on the maximum surface stress in ceramics during quenching
}

\author{
Y. F. Shao, F. Song, C. P. Jiang, X. H. Xu, J. C. Wei \& Z. L. Zhou
}

To cite this article: Y. F. Shao, F. Song, C. P. Jiang, X. H. Xu, J. C. Wei \& Z. L. Zhou (2016) Effect of temperature-dependent surface heat transfer coefficient on the maximum surface stress in ceramics during quenching, Philosophical Magazine, 96:4, 387-398, DOI: 10.1080/14786435.2015.1134836

To link to this article: http://dx.doi.org/10.1080/14786435.2015.1134836

\section{曲 Published online: 25 Jan 2016.}

\section{Submit your article to this journal $\longleftarrow$}

Џll Article views: 44

Q View related articles $\sqsubset$

View Crossmark data $\longleftarrow$ 


\title{
Effect of temperature-dependent surface heat transfer coefficient on the maximum surface stress in ceramics during quenching
}

\author{
Y. F. Shao ${ }^{a}$, F. Song ${ }^{a}$, C. P. Jiang ${ }^{a}$, X. H. Xu ${ }^{\text {a }}$, J. C. Wei ${ }^{a}$ and Z. L. Zhou ${ }^{b}$
}

aState Key Laboratory of Nonlinear Mechanics (LNM), Institute of Mechanics, Chinese Academy of Sciences, Beijing, China; b306 Institute, The Third Academy of China Aerospace Science and Industry Corporation, Beijing, China

\begin{abstract}
We study the difference in the maximum stress on a cylinder surface $\sigma_{\max }$ using the measured surface heat transfer coefficient $h_{\mathrm{m}}$ instead of its average value $h_{\mathrm{a}}$ during quenching. In the quenching temperatures of $200,300,400,500,600$ and $800^{\circ} \mathrm{C}$, the maximum surface stress $\sigma_{\operatorname{mmax}}$ calculated by $h_{\mathrm{m}}$ is always smaller than $\sigma_{\text {amax }}$ calculated by $h_{\mathrm{a}^{\prime}}$ except in the case of $800^{\circ} \mathrm{C}$; while the time to reach $\sigma_{\text {max }}$ calculated by $h_{\mathrm{m}}\left(f_{\text {mmax }}\right)$ is always earlier than that by $h_{\mathrm{a}}\left(f_{\text {amax }}\right)$. It is inconsistent with the traditional view that $\sigma_{\text {max }}$ increases with increasing Biot number and the time to reach $\sigma_{\max }$ decreases with increasing Biot number. Other temperature-dependent properties also have a small effect on the trend of their mutual ratios with quenching temperatures. Such a difference between the two maximum surface stresses is caused by the dramatic variation of $h_{m}$ with temperature, which needs to be considered in engineering analysis.
\end{abstract}

\section{ARTICLE HISTORY}

Received 29 September 2015 Accepted 16 December 2015

\section{KEYWORDS}

Thermomechanical; ceramics; stress analysis; thermal shock

\section{Introduction}

The sudden catastrophic reduction in the strength of materials in thermal shock is a long-standing problem in the thermostructural applications of ceramics [1-3]. The mechanism of reduction is traditionally considered to be crack initiation when the stresses induced by a thermal gradient exceed the strength of materials [4,5]. Generally, ceramics are much weaker in tension than in compression, so the maximum tensile stress on the surface of ceramics is of primary interest [6,7].

Based on thermoelastic mechanics, the dimensionless stress on the surface of ceramics with various shapes (the sphere, the plate or the cylinder) during quenching under different thermal shock conditions typically appears as shown in Figure 1 [8-10]. It is clear that each of the curves in Figure 1 has a maximum value $\sigma_{\max }$. The magnitude of $\sigma_{\max }$ increases with increasing Biot number $\beta=h R / k$, while the time $f_{\max }$ when the thermal stress reaches its maximum value decreases with increasing $\beta$, where $h$ is the surface heat transfer coefficient 


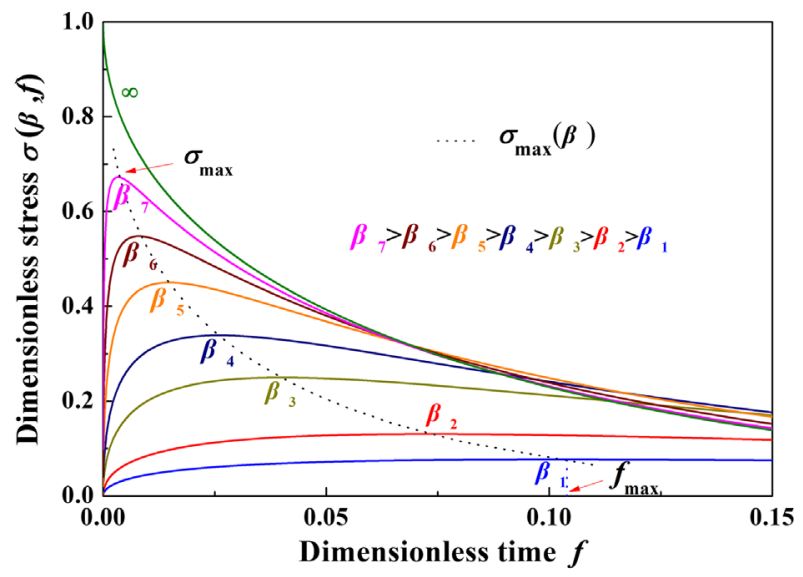

Figure 1. (colour online) Dimensionless stress at the surface of ceramics with various shapes (the sphere, the plate or the cylinder) during quenching under different thermal shock conditions, where the magnitude of the maximum surface stress $\sigma_{\max }$ increases with increasing Biot number $\beta$, and the time $f_{\max }$ when the thermal stress reaches its maximum value decreases with increasing $\beta$.

between the material and the medium, and $k$ and $R$ are the thermal conductivity and the characteristic dimension of the material, respectively. Since it was reported in 1945 by Jaeger, various aspects of $\sigma_{\max }$ have been studied, most importantly the determination of the magnitude and the arrival time of $\sigma_{\max }[11,12]$. A semi-empirical equation of $\sigma_{\max }$ and $\beta$ was suggested by Manson and this relation has subsequently been widely used to calculate the resistance of both brittle and ductile materials to crack initiation under cold shock conditions $[9,13,14]$. In the previous studies, the surface heat transfer coefficient used in the calculation is considered as a constant or an average value. However, the surface heat transfer coefficient largely depends not only on the initial quenching temperature but also on its evolution in quenching media $[15,16]$. How does the real surface heat transfer coefficient influence the evolution of the surface stress in quenching? Rarely has research focused on this issue, which is of practical importance in engineering analysis. The purpose of this paper is to consider the difference in the maximum surface stress of ceramics arising from the measured surface heat transfer coefficient $h_{\mathrm{m}}$ instead of its average value $h_{\mathrm{a}}$ during quenching.

Firstly, we use $h_{\mathrm{m}}$ and $h_{\mathrm{a}}$ to calculate the thermal fields. Then, we use the thermal fields to calculate the surface stress fields. By comparing the two stress fields, we examine the influences of surface heat transfer coefficient on the magnitude and the arrival time of $\sigma_{\max }$. At the same time, we also examine the influence of other temperature-dependent physical parameters on $\sigma_{\max }$

\section{Methods and calculations}

\subsection{Surface heat transfer coefficient}

We have measured the temperature-dependent surface heat transfer coefficient $h_{\mathrm{m}}$ of $\mathrm{Al}_{2} \mathrm{O}_{3}$ ceramics quenched from different initial temperatures $T_{0}$ into a water bath at room temperature $T_{\infty}$ [17]. In measurement, the thermocouple instrumented specimens with the 
dimensions of $150 \mathrm{~mm}$ in height and $50 \mathrm{~mm}$ in diameter were first heated at a preset temperature, then they were dropped into a water bath by free fall at $5 \mathrm{~cm}$ high from the surface of the water, and the depth of the bath is about $1 \mathrm{~m}$. The specimens touched the wire mesh at the bath bottom while measuring. The details are given elsewhere [17].

The coefficient is a function of the surface temperature $T_{\mathrm{s}}$ of ceramics during the water quench. The measured data are shown in Figure 2 and Table 1 . The average value $h_{\mathrm{a}}$ of each surface heat transfer coefficient curve is defined to be

$$
h_{\mathrm{a}}=\frac{1}{T_{0}-T_{\infty}} \int_{T_{\infty}}^{T_{0}} h\left(T_{s}\right) \mathrm{d} T_{s}
$$

It is observed that $h_{\mathrm{m}}$ and $h_{\mathrm{a}}$ can be divided into three regions. In the regions I and III, $h_{\mathrm{a}}$ is larger than $h_{\mathrm{m}}$; while in region II, $h_{\mathrm{a}}$ is less than $h_{\mathrm{m}}$. In addition, with increasing initial temperature, the range of region I is gradually expanding.

\subsection{Temperature distribution}

Based on previous experiments [17], we consider an infinite length cylinder of radius $R$, with a uniform initial temperature $T_{0}$. At the initial time, the surface of the cylinder is suddenly exposed to a convective medium with a uniform temperature $T_{\infty}$, as shown in Figure 3 .

The temperature field change in the cylinder $T=T(r, \tau)$ satisfies the equation of heat conduction

$$
\frac{\partial T}{\partial \tau}=a\left(\frac{\partial^{2} T}{\partial r^{2}}+\frac{\partial T}{r \partial r}\right)
$$

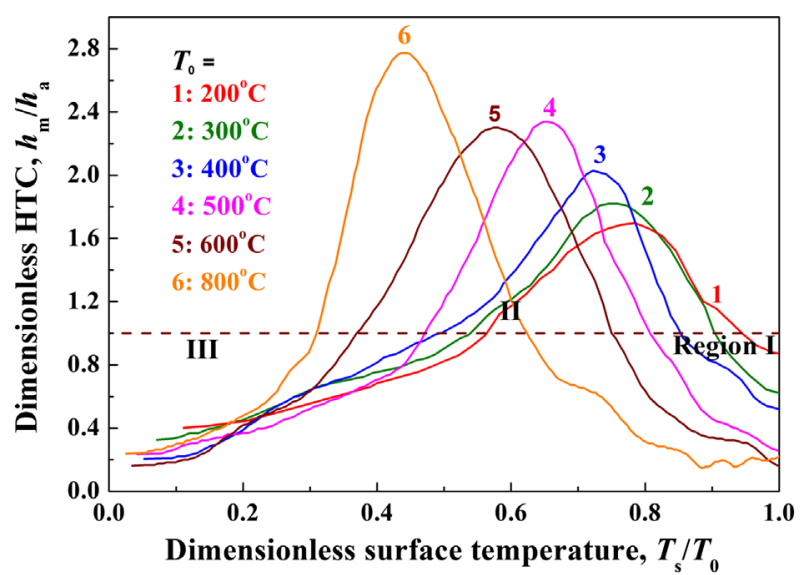

Figure 2. (colour online) Dimensionless surface heat transfer coefficients $h_{\mathrm{m}} / h_{\mathrm{a}}$ for $\mathrm{Al}_{2} \mathrm{O}_{3}$ ceramic bars quenched into the room temperature water bath from different initial temperatures $T_{0}$ are shown as the functions of the transient surface temperatures $T_{s}$ of the specimens.

Table 1. Average surface heat transfer coefficient $h_{\mathrm{a}}$ for different initial quenching temperatures $T_{0}$.

\begin{tabular}{lllllll}
\hline$T_{0}\left({ }^{\circ} \mathrm{C}\right)$ & 200 & 300 & 400 & 500 & 600 & 800 \\
\hline$h_{\mathrm{a}}\left(10^{4} \mathrm{~W} \mathrm{~m}^{-2} \mathrm{~K}^{-1}\right)$ & 0.87 & 0.89 & 0.93 & 1.11 & 1.23 & 1.05 \\
\hline
\end{tabular}




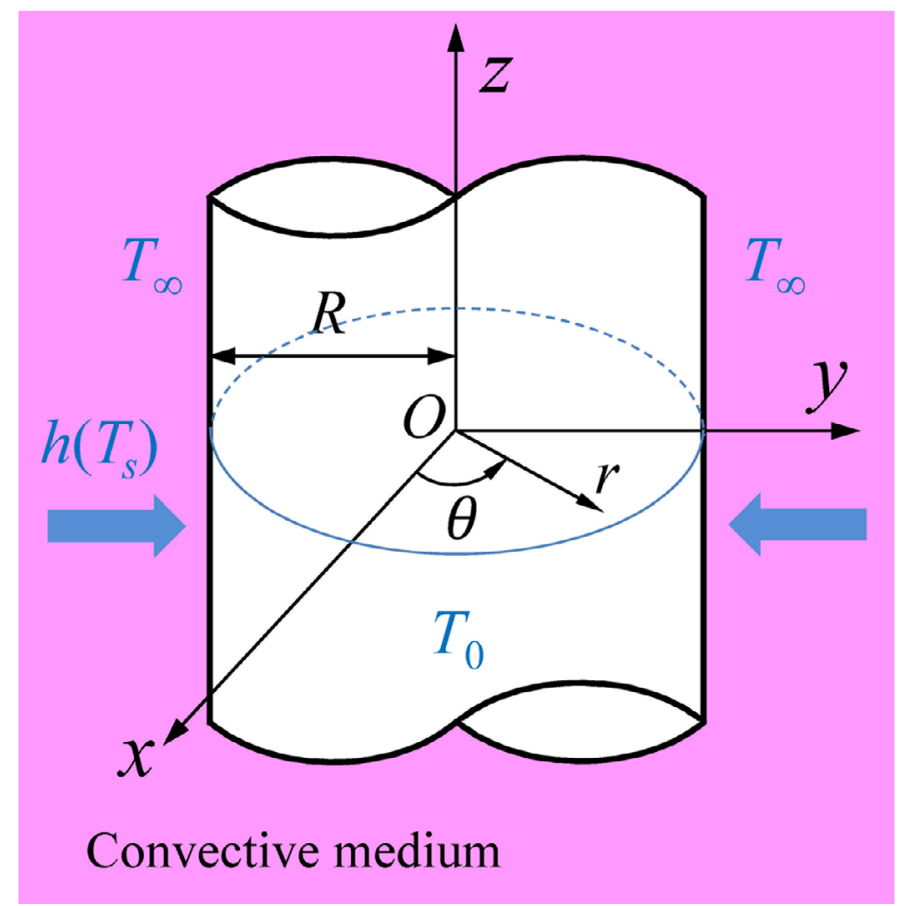

Figure 3. (colour online) An infinitely long cylinder with radius $R$ and initial temperature $T_{0}$ is suddenly exposed to a convective medium of temperature $T_{\infty}$, in which the surface heat transfer coefficient of the materials $h\left(T_{\mathrm{s}}\right)$ is the function of surface temperature $T_{\mathrm{s}}$.

where $r$ is the coordinate with the origin at the centre of the cylinder; $\tau$ is time; $a=k / \rho c_{\mathrm{p}}$ is the thermal diffusivity of the material of the cylinder; $k, \rho$ and $c_{\mathrm{p}}$ are the thermal conductivity, the density and the specific heat at constant pressure for the material, respectively.

The initial and boundary conditions that Equation (2) satisfied are written by

$$
\begin{aligned}
& T(r, 0)=T_{0}, \\
& \left.\frac{\partial T}{\partial r}\right|_{r=0}=0,
\end{aligned}
$$

and

$$
-\left.k \frac{\partial T}{\partial r}\right|_{r=R}=h\left(T-T_{\infty}\right) .
$$

\begin{tabular}{|c|c|c|c|c|c|}
\hline $\begin{array}{l}\text { Young modulus } \\
E(\mathrm{GPa})[10]\end{array}$ & $\begin{array}{c}\text { Poisson's ratio } \\
v[10]\end{array}$ & $\begin{array}{c}\text { Density } \rho \\
\left(\mathrm{kg} \mathrm{m}^{-3}\right)[17]\end{array}$ & $\begin{array}{l}\text { Heat capacity c } \\
\left(\mathrm{J} \mathrm{kg}^{-1} \mathrm{~K}^{-1}\right)[17]\end{array}$ & $\begin{array}{c}\text { Thermal } \\
\text { conductivity } \\
k\left(\mathrm{~W} \mathrm{~m}^{-1} \mathrm{~K}^{-1}\right) \\
{[17]}\end{array}$ & $\begin{array}{c}\text { Coefficient of } \\
\text { thermal expan- } \\
\text { sion } \alpha\left(10^{-6} \mathrm{~K}^{-1}\right) \\
{[10]}\end{array}$ \\
\hline 378 & 0.22 & 3850 & 950 & 20 & 8.0 \\
\hline
\end{tabular}

Table 2. Mechanical and thermal parameters of alumina used in calculation. 
Assuming that the properties of the material do not vary with temperature, we can use standard separation-of-variables technique to solve Equation (2) and obtain the following [18]

$$
\frac{T-T_{0}}{T_{\infty}-T_{0}}=1-2 \sum_{n=1}^{\infty} \frac{J_{1}\left(\beta_{n}\right)}{\beta_{n}\left[J_{0}^{2}\left(\beta_{n}\right)+J_{1}^{2}\left(\beta_{n}\right)\right]} \exp \left(-\beta_{n}^{2} \cdot f\right) J_{0}\left(\beta_{n} \cdot r^{*}\right)
$$

where $f=a \tau / R^{2}$ is the dimensionless time of heat conduction; $r^{*}=r / R$ stands for the dimensionless coordinate; $\beta_{n}$ are the roots of the equation

$$
\beta_{n} \frac{J_{1}\left(\beta_{n}\right)}{J_{0}\left(\beta_{n}\right)}=\beta
$$

When the surface heat transfer coefficient $h$ is a function of surface temperature, which satisfies the non-linear boundary conditions, the analytical solution of temperature field cannot be obtained directly from the separation of variables. But if the entire thermal shock process is divided into $n$ small time intervals, and assuming the heat transfer coefficient does not vary with temperature in each interval, we can use the Equation (6) to obtained the temperature field of the first time interval $[0, \Delta f]\left(\Delta f=10^{-5}\right)$; and then the obtained temperature was calculated as the initial value of the temperature distribution in the next time interval, so to solve the Equation (6) again we can obtained the temperature field of the second time interval $[\Delta f, 2 \Delta f]$; repeating the process described above, we can obtain an approximate numerical solution of the whole process. The mechanical and thermal parameters of alumina used in calculation are given in Table 2.

\subsection{Surface stress distribution}

According to the theory of thermal stresses [19], we readily write the thermal stress field in the cylinder as

$$
\begin{gathered}
\sigma_{r}(r, \tau)=\frac{\alpha E}{1-v}\left[\frac{1}{R^{2}} \int_{0}^{R}\left(T-T_{0}\right) r \mathrm{~d} r-\frac{1}{r^{2}} \int_{0}^{r}\left(T-T_{0}\right) r \mathrm{~d} r\right], \\
\sigma_{\theta}(r, \tau)=\frac{\alpha E}{1-v}\left[\frac{1}{R^{2}} \int_{0}^{R}\left(T-T_{0}\right) r \mathrm{~d} r+\frac{1}{r^{2}} \int_{0}^{r}\left(T-T_{0}\right) r \mathrm{~d} r-\left(T-T_{0}\right)\right], \\
\sigma_{z}(r, \tau)=\frac{\alpha E}{1-v}\left[\frac{2}{R^{2}} \int_{0}^{R}\left(T-T_{0}\right) r \mathrm{~d} r-\left(T-T_{0}\right)\right] .
\end{gathered}
$$

Based on Liu's study [12], the maximum tensile thermal stress is the axial stress $\sigma_{\mathrm{z}}$ on the surface of the cylinder during quenching. Accordingly, in the following, we only focus on $\sigma_{\mathrm{z}}$ on the surface. 
For the convenience of comparing the values of thermal stresses, the dimensionless thermal stress is then defined as [12]

$$
\sigma_{z}^{*}(r, \tau)=\frac{\sigma_{z}(r, \tau) \cdot(1-v)}{\alpha E\left(T_{\infty}-T_{0}\right)} .
$$

Once the temperature field is determined in each time interval, the transient surface stress can be obtained by Equation (11) in each time interval.

\subsection{Finite element model for calculating surface stress}

In order to consider the effect of other temperature-dependent properties of alumina on the surface stress, we use the Finite Element (FE) software ANSYS to calculate the surface stress. As shown in Figure 4, the thermal conductivity [20], specific heat [20] and thermal expansion coefficient are strongly temperature-dependent in the range $20-800{ }^{\circ} \mathrm{C}$ [21]. But the Young's modulus, Poisson's ratio and density is regarded as temperature-independent [22], as shown in Table 2.

\section{Results and discussion}

Using the data of $h_{\mathrm{m}}$ and $h_{\mathrm{a}}$, the temperature fields occur in the cylinder for different initial quenching temperatures (different Biot numbers) during cooling are readily calculated by solving Equation (6), as shown in Figure 5(a)-(d). Comparing the two temperature fields, we find that for all the quenching temperatures, the temperature fields in the position of the axis, the middle layer and the surface of cylindrical specimen, calculated by $h_{\mathrm{a}}$ are substantially lower than that by $h_{\mathrm{m}}$, except the initial period in the surface temperature field of the cylinder, as shown in the enlarged pictures.

We can see that, initially, the surface temperature $T_{\mathrm{sa}}$ calculated with $h_{\mathrm{a}}$ drops more sharply than the surface temperature $T_{\text {sm }}$ with $h_{\mathrm{m}}$, which means the amount of heat transferred in this period is estimated to be greater than in the calculation based on $h_{\mathrm{m}}$, as $h_{\mathrm{a}}$ is larger than $h_{\mathrm{m}}$ in region I. With increasing initial temperature, the time period when $T_{\mathrm{sa}}$ is lower than $T_{\mathrm{sm}}$ becomes longer, because the range of the region I is gradually expanding with increasing initial temperature. Then, $T_{\text {sa }}$ gradually becomes higher than $T_{\mathrm{sm}}$ as $h_{\mathrm{a}}$ is less than $h_{\mathrm{m}}$ in region II. Finally, $T_{\mathrm{sa}}$ become lower than $T_{\mathrm{sm}}$ again as $h_{\mathrm{a}}$ is
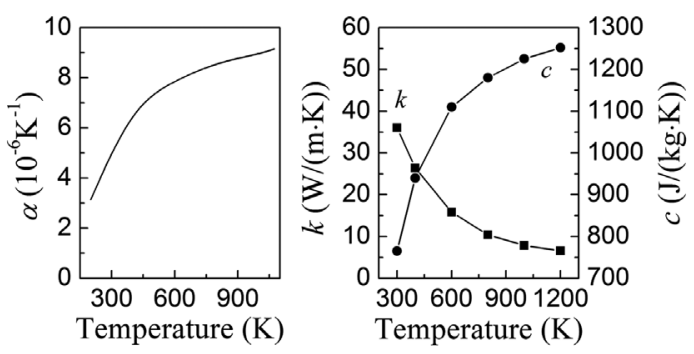

Figure 4. Graphs of the thermal conductivity $k$ [20], the specific heat $c[20]$ and the coefficient of thermal expansion $\alpha$ [21] of $\mathrm{Al}_{2} \mathrm{O}_{3}$ ceramics vs. temperature. 
Time (s)

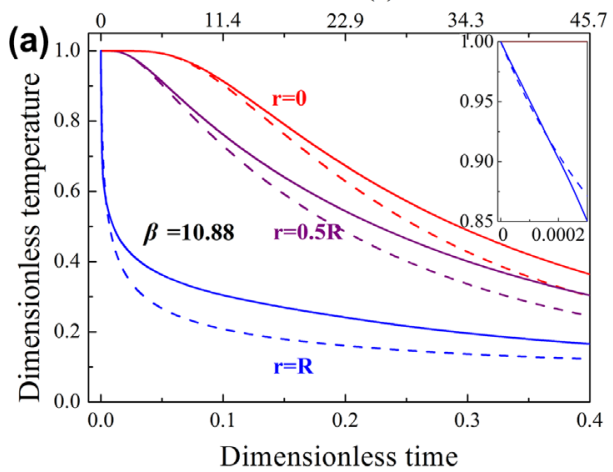

Time (s)

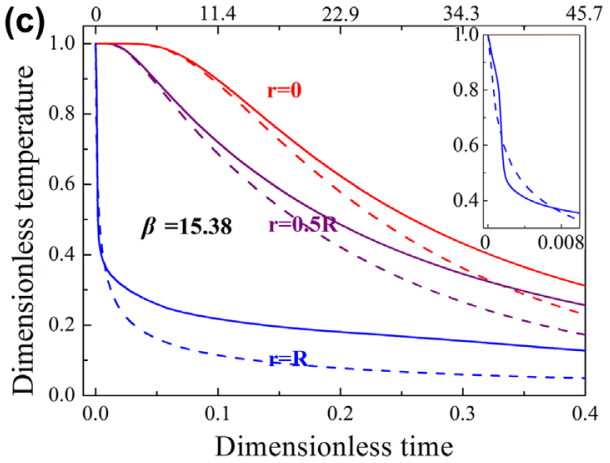

Time (s)

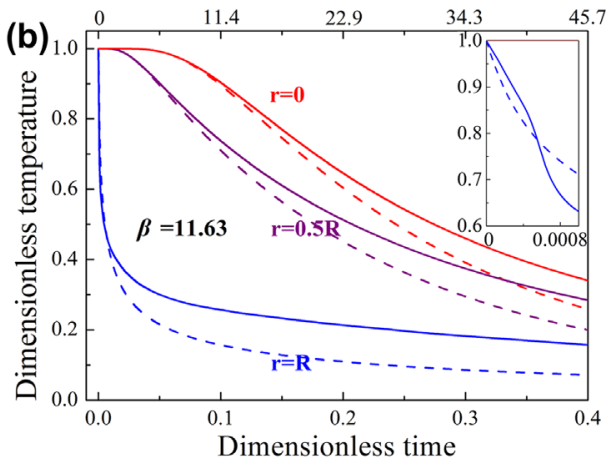

Time (s)

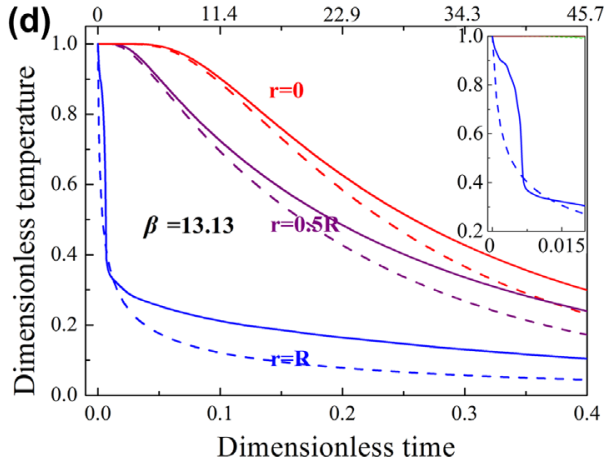

Figure 5. (colour online) Comparison between the temperature fields obtained by the measured heat transfer coefficient (the solid line) and the average heat transfer coefficient (the dotted line), for initial quenching temperature $T_{0}=$ (a) $200^{\circ} \mathrm{C}$, (b) $400{ }^{\circ} \mathrm{C}$, (c) $600^{\circ} \mathrm{C}$, (d) $800{ }^{\circ} \mathrm{C}$, where $r=0,0.5 R, R$ represent the position of the axis, the middle layer and the surface of the cylindrical specimen, respectively.

larger than $h_{\mathrm{m}}$ in region III, which made the temperature fields calculated by $h_{\mathrm{a}}$ lower than that by $h_{\mathrm{m}}$ in the later time.

The thermal stress fields calculated by $h_{\mathrm{m}}$ and $h_{\mathrm{a}}$ for different initial quenching temperatures are shown in Figure 6(a)-(d). Referring to the insets in Figure 6, initially, the surface stress $\sigma_{\text {sm }}$ calculated with $h_{\mathrm{m}}$ is slightly lower than the surface stress $\sigma_{\text {sa }}$ calculated by $h_{\mathrm{a}}$, and the time period when $\sigma_{\mathrm{sm}}$ is lower than $\sigma_{\mathrm{sa}}$ becomes longer with increasing initial temperature. Then, $\sigma_{\mathrm{sm}}$ become higher than $\sigma_{\mathrm{sa}}$. Finally, $\sigma_{\mathrm{sm}}$ become lower than $\sigma_{\mathrm{sa}}$ again, corresponding to the different temperature profiles in Figure 5.

To indicate the influences of the temperature-dependent heat transfer coefficient on the magnitude and the arrival time of $\sigma_{\max }$, the comparison between the thermal stresses on the surface obtained by $h_{\mathrm{m}}$ and $h_{\mathrm{a}}$ for different initial quenching temperatures is shown in Figure 7. When using data of $h_{\mathrm{a}}$, we can find that, the magnitude of the maximum surface stress $\sigma_{\operatorname{amax}}$ are $\sigma_{600{ }^{\circ} \mathrm{C}}>\sigma_{500{ }^{\circ} \mathrm{C}}>\sigma_{800{ }^{\circ} \mathrm{C}}>\sigma_{400{ }^{\circ} \mathrm{C}}>\sigma_{300{ }^{\circ} \mathrm{C}}>\sigma_{200{ }^{\circ} \mathrm{C}}$, and that the time to reach the maximum surface stress $f_{\text {amax }}$ are $f_{600{ }^{\circ} \mathrm{C}}<f_{500{ }^{\circ} \mathrm{C}}<f_{800{ }^{\circ} \mathrm{C}}<f_{400}$ ${ }^{\circ} \mathrm{C}<f_{300{ }^{\circ} \mathrm{C}}<f_{200{ }^{\circ} \mathrm{C}}$, respectively. It is consistent with traditional view that $f_{\max }$ decreases with increasing $\beta$ and $\sigma_{\max }$ increases with increasing $\beta$ [8-10]. While using data of $h_{\mathrm{m}}$,

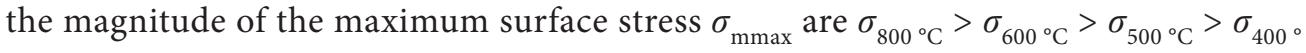


Time (s)

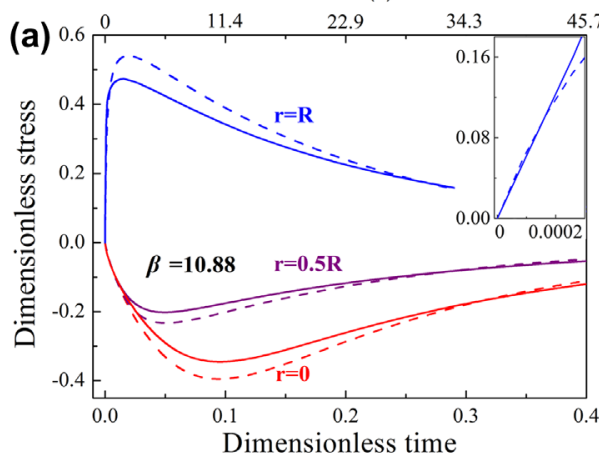

Time (s)

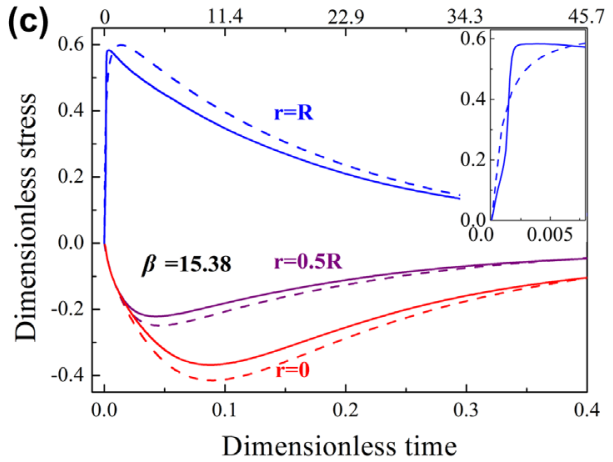

Time (s)

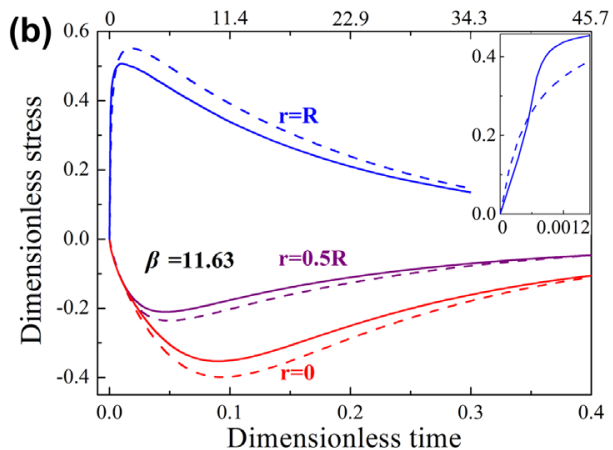

Time (s)

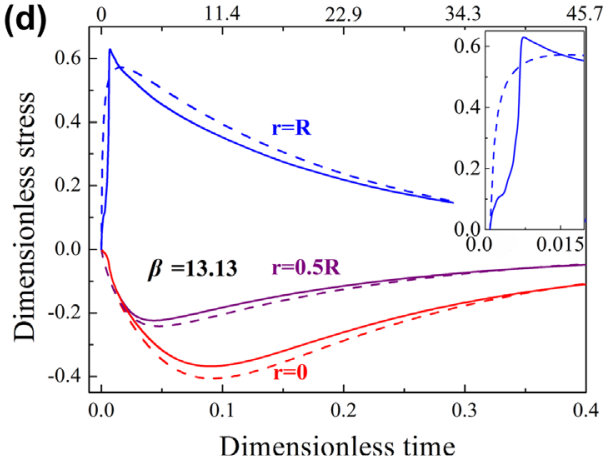

Figure 6. (colour online) Comparison of the thermal stress fields obtained by the measured heat transfer coefficient (the solid line) and the average heat transfer coefficient (the dotted line), for initial quenching temperature $T_{0}=$ (a) $200{ }^{\circ} \mathrm{C}$, (b) $400{ }^{\circ} \mathrm{C}$, (c) $600{ }^{\circ} \mathrm{C}$, (d) $800{ }^{\circ} \mathrm{C}$, where $r=0,0.5 R, R$ represent the position of the axis, the middle layer and the surface of cylindrical specimen, respectively.

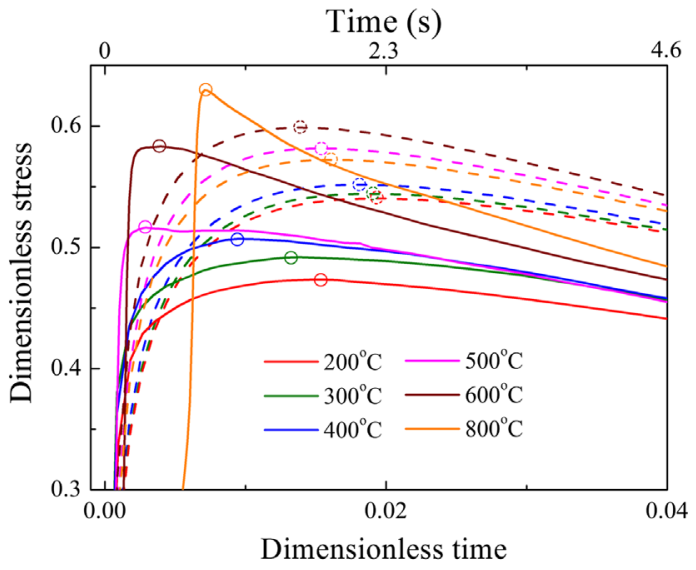

Figure 7. (colour online) Comparison between the thermal stress at the surface obtained by the measured heat transfer coefficient (the solid lines) and the average heat transfer coefficient (the dotted lines), for different initial quenching temperatures. The marks represent the maximum stresses. 
C $>\sigma_{300{ }^{\circ} \mathrm{C}}>\sigma_{200{ }^{\circ} \mathrm{C}}$, and the time to reach the maximum surface stress $f_{\operatorname{mmax}}$ are $f_{500{ }^{\circ} \mathrm{C}}<f$ $600{ }^{\circ} \mathrm{C}<f_{800{ }^{\circ} \mathrm{C}}<f_{400{ }^{\circ} \mathrm{C}}<f_{300{ }^{\circ} \mathrm{C}}<f_{200{ }^{\circ} \mathrm{C}}$, respectively. Therefore, when the initial quenching temperature $T_{0} \leq 400{ }^{\circ} \mathrm{C}$, it follows the traditional view before; while in the case of $T_{0}>400{ }^{\circ} \mathrm{C}$, it does not obey this rule.

In addition, we find that in all the quenching temperatures, the magnitude of $\sigma_{\max }$ calculated by $h_{\mathrm{m}}$ is always lower than that by $h_{\mathrm{a}}$, except $T_{0}>600{ }^{\circ} \mathrm{C}$, as listed in Table 3. The ratio $\left(\sigma_{\operatorname{amax}}-\sigma_{\max }\right) / \sigma_{\operatorname{mmax}}$ decreases from $14.1 \%$ at $200^{\circ} \mathrm{C}$ to $-9.1 \%$ at $800{ }^{\circ} \mathrm{C}$ and the change is not great. Thus, from the point of view of stress magnitude, the traditional usage of $h_{\mathrm{a}}$ instead of $h_{\mathrm{m}}$ is roughly reasonable during the ceramic quenching. Further, we find that in all the quenching temperatures, the time to reach the maximum stress calculated by $h_{\mathrm{m}}$ is always earlier than that by $h_{\mathrm{a}}$, as listed in Table 4 . The ratio $\left(f_{\operatorname{amax}}-f_{\operatorname{mmax}}\right) / f_{\operatorname{mmax}}$ increases from $22.4 \%$ at $200^{\circ} \mathrm{C}$ to $437.9 \%$ at $500^{\circ} \mathrm{C}$, and the change is substantially greater than that in the magnitude of $\sigma_{\max }$. Thus, when the time factor is important, such as short-time thermal shock [23], it is not a good strategy to use $h_{\mathrm{a}}$ instead of $h_{\mathrm{m}}$.

Considering the temperature-dependent properties of thermal conductivity, specific heat and thermal expansion coefficient, a comparison between the thermal stresses on the surface obtained by $h_{\mathrm{m}}$ and $h_{\mathrm{a}}$ for different initial quenching temperatures is shown in Figure 8. When using data of $\mathrm{h}_{\mathrm{a}}$, the magnitude of the maximum surface stress $\sigma_{\text {amax }}$ are $\sigma$ $800^{\circ} \mathrm{C}>\sigma_{600{ }^{\circ} \mathrm{C}}>\sigma_{500^{\circ} \mathrm{C}}>\sigma_{400^{\circ} \mathrm{C}}>\sigma_{300^{\circ} \mathrm{C}}>\sigma_{200^{\circ} \mathrm{C}}$, and the time to reach the maximum surface stress $f_{\text {amax }}$ are $f_{600^{\circ} \mathrm{C}}<f_{800^{\circ} \mathrm{C}}<f_{500^{\circ} \mathrm{C}}<f_{400^{\circ} \mathrm{C}}<f_{200^{\circ} \mathrm{C}}<f_{300^{\circ} \mathrm{C}}$, respectively. While using data of $h_{\mathrm{m}}$, the magnitude of the maximum surface stress $\sigma_{\operatorname{mmax}}$ are $\sigma_{800^{\circ} \mathrm{C}}>\sigma_{600^{\circ} \mathrm{C}}>\sigma_{500^{\circ} \mathrm{C}}>\sigma_{4}$ ${ }_{00}^{\circ} \mathrm{C}>\sigma_{300^{\circ} \mathrm{C}}>\sigma_{200^{\circ} \mathrm{C}}$, and the time to reach the maximum surface stress $f_{\operatorname{mmax}}$ are $f_{500^{\circ} \mathrm{C}}<f$

Table 3. Magnitude of the maximum surface stress $\sigma_{\max }$ calculated by the measured surface heat transfer coefficient $\left(\sigma_{\operatorname{mmax}}\right)$ and the average surface heat transfer coefficient $\left(\sigma_{\text {amax }}\right)$, for different initial quenching temperatures $T_{0}$.

\begin{tabular}{lcccccc}
\hline$T_{0}\left({ }^{\circ} \mathrm{C}\right)$ & 200 & 300 & 400 & 500 & 600 & 800 \\
\hline$\sigma_{\operatorname{amax}}$ & 0.5403 & 0.5441 & 0.5517 & 0.5816 & 0.5987 & 0.5722 \\
$\sigma_{\operatorname{mmax}}$ & 0.4735 & 0.4919 & 0.5070 & 0.5162 & 0.5832 & 0.6295 \\
$\left(\sigma_{\operatorname{amax}}-\sigma_{\operatorname{mmax}}\right) / \sigma_{\operatorname{mmax}}$ & $14.1 \%$ & $10.6 \%$ & $8.8 \%$ & $12.7 \%$ & $2.7 \%$ & $-9.1 \%$ \\
\hline
\end{tabular}

Table 4. Time to reach the maximum stress $f_{\max }$ calculated by the measured surface heat transfer coefficient $\left(f_{\operatorname{mmax}}\right)$ and the average surface heat transfer coefficient $\left(f_{\text {amax }}\right)$, for different initial quenching temperatures $T_{0}$.

\begin{tabular}{lcccccc}
\hline$T_{0}\left({ }^{\circ} \mathrm{C}\right)$ & 200 & 300 & 400 & 500 & 600 & 800 \\
\hline$f_{\operatorname{amax}}$ & 0.0191 & 0.0190 & 0.0181 & 0.0156 & 0.0138 & 0.0164 \\
$f_{\operatorname{mmax}}$ & 0.0156 & 0.0138 & 0.0095 & 0.0029 & 0.0040 & 0.0071 \\
$\left(f_{\operatorname{amax}}-f_{\text {mmax }}\right) / f_{\operatorname{mmax}}$ & $22.4 \%$ & $37.7 \%$ & $90.5 \%$ & $437.9 \%$ & $245.0 \%$ & $131.0 \%$ \\
\hline
\end{tabular}

Table 5. In the case of FE analyses using the temperature dependent thermal properties, the magnitude of the maximum surface stress $\sigma_{\max }$ calculated by the measured surface heat transfer coefficient $\left(\sigma_{\operatorname{mmax}}\right)$ and the average surface heat transfer coefficient $\left(\sigma_{\text {amax }}\right)$, for different initial quenching temperatures $T_{0}$.

\begin{tabular}{lcccccc}
\hline$T_{0}\left({ }^{\circ} \mathrm{C}\right)$ & 200 & 300 & 400 & 500 & 600 & 800 \\
\hline$\sigma_{\operatorname{amax}}$ & 0.5844 & 0.6105 & 0.6505 & 0.7177 & 0.7571 & 0.7832 \\
$\sigma_{\operatorname{mmax}}$ & 0.5275 & 0.5557 & 0.6199 & 0.6820 & 0.7710 & 0.8711 \\
$\left(\sigma_{\operatorname{amax}}-\sigma_{\operatorname{mmax}}\right) / \sigma_{\operatorname{mmax}}$ & $11.2 \%$ & $9.9 \%$ & $4.9 \%$ & $5.2 \%$ & $-1.8 \%$ & $-10.1 \%$ \\
\hline
\end{tabular}


Table 6. In the case of FE analyses using the temperature dependent thermal properties, the time to reach the maximum stress $f_{\max }$ calculated by the measured surface heat transfer coefficient $\left(f_{\operatorname{mmax}}\right)$ and the average surface heat transfer coefficient $\left(f_{\text {amax }}\right)$, for different initial quenching temperatures $T_{0}$.

\begin{tabular}{lcccccc}
\hline$T_{0}\left({ }^{\circ} \mathrm{C}\right)$ & 200 & 300 & 400 & 500 & 600 & 800 \\
\hline$f_{\operatorname{amax}}$ & 0.0156 & 0.0203 & 0.0142 & 0.0115 & 0.0105 & 0.0109 \\
$f_{\operatorname{mmax}}$ & 0.0124 & 0.0095 & 0.0099 & 0.0021 & 0.0023 & 0.0051 \\
$\left(f_{\operatorname{amax}}-f_{\max }\right) / f_{\max }$ & $25.8 \%$ & $113.7 \%$ & $42.6 \%$ & $455.1 \%$ & $348.5 \%$ & $113.5 \%$ \\
\hline
\end{tabular}

$600^{\circ} \mathrm{C}<f_{800^{\circ} \mathrm{C}}<f_{300^{\circ} \mathrm{C}}<f_{400^{\circ} \mathrm{C}}<f_{200^{\circ} \mathrm{C}}$, respectively. It is indicated that they do not follow the traditional view anymore. Therefore, the other temperature-dependent properties have a certain effect on the magnitude and the arrival time of $\sigma_{\max }$. However, the effect on the trend of their mutual ratios with quenching temperatures is small, as listed in Tables 3-6. The ratio $\left(\sigma_{\operatorname{amax}}-\sigma_{\operatorname{mmax}}\right) / \sigma_{\operatorname{mmax}}$ decreases from $11.2 \%$ at $200^{\circ} \mathrm{C}$ to $-10.1 \%$ at $800^{\circ} \mathrm{C}$ and the ratio $\left(\mathrm{f}_{\mathrm{amax}}-f_{\operatorname{mmax}}\right) / f_{\operatorname{mtmax}}$ increases from $25.8 \%$ at $200^{\circ} \mathrm{C}$ to $455.1 \%$ at $500^{\circ} \mathrm{C}$. We believe that the cause of this difference between the two maximum surface stresses is the features of $h_{\mathrm{m}}$, which first increases to reach a maximum value and afterwards decreases as the surface temperature decreases. Note that the changes with temperature in other properties (Young's modulus, Poisson's ratio and density) are much smaller, and in this study they have been ignored.

In addition, Cheng used a method similar to us to investigate the surface heat transfer coefficient $\mathrm{h}$ of steel cylinders with the dimensions of $60 \mathrm{~mm}$ in height and $20 \mathrm{~mm}$ in diameter [24], which is 0.4 of our samples in height and diameter, respectively. We find that the feature of $h$ in Cheng's study is similar to us. Thus, our results may be also valid for the specimens with similar dimensions and shapes. To provide more precise instructions to engineering analysis, further studies should be conducted to identify how the surface heat transfer coefficient changes with the size.

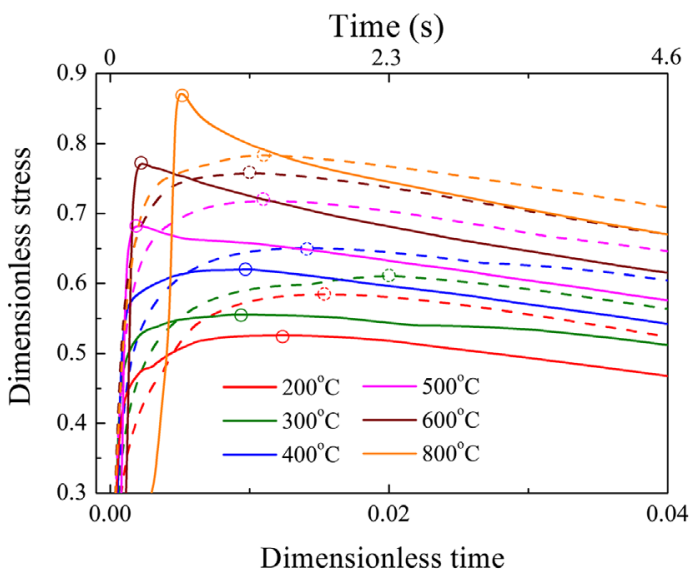

Figure 8. (colour online) In the case of FE analyses using the temperature-dependent thermal properties, the comparison between the thermal stress at the surface obtained by the measured heat transfer coefficient (the solid lines) and the average heat transfer coefficient (the dotted lines), for different initial quenching temperatures. The marks represent the maximum stresses. 


\section{Conclusions}

When the initial quenching temperature is $T_{0} \leq 400^{\circ} \mathrm{C}$, the maximum surface stress $\sigma_{\max }$ and the time to reach the maximum surface stress $f_{\max }$ calculated by measured surface heat transfer coefficient $h_{\mathrm{m}}$ are consistent with the traditional view that $\sigma_{\max }$ increases with increasing Biot number and $f_{\max }$ decreases with increasing Biot number; while $T_{0}>400^{\circ} \mathrm{C}$, it does not obey this rule. However, in the case of other temperature-dependent physical parameters, they do not follow the traditional view anymore. As a result, using average surface heat transfer coefficient $h_{\mathrm{a}}$ instead of $h_{\mathrm{m}}$ will introduce a small error in the magnitude of $\sigma_{\max }$, however, the error introduces in the arrival time of $\sigma_{\max }$ is significant.

\section{Acknowledgement}

This work is supported by the National Natural Science Foundation of China [grant number 11102208], [grant number 11232013], [grant number 11472285] and [grant number 11572326].

\section{Disclosure statement}

No potential conflict of interest was reported by the authors.

\section{References}

[1] R. Danzer, T. Lube, P. Supancic, and R. Damani, Fracture of ceramics, Adv. Eng. Mater. 10 (2008), p. 275-298.

[2] B. Bourdin, J.J. Marigo, C. Maurini, and P. Sicsic, Morphogenesis and propagation of complex cracks induced by thermal shocks, Phys. Rev. Lett. 112 (2014), p. 014301.

[3] F. Song, S.H. Meng, X.H. Xu, and Y.F. Shao, Enhanced thermal shock resistance of ceramics through biomimetically inspired nanofins, Phys. Rev. Lett. 104 (2010), p. 125502.

[4] W.D. Kingery, Factors affecting thermal stress resistance of ceramic materials, J. Am. Ceram. Soc. 38 (1955), p. 3-15.

[5] J. Li, F. Song, and C.P. Jiang, Direct numerical simulations on crack formation in ceramic materials under thermal shock by using a non-local fracture model, J. Eur. Ceram. Soc. 33 (2013), p. 2677-2687.

[6] W.D. Kingery, H.K. Bowen, and D.R. Uhlmann, Introduction to Ceramics, Wiley, New York, 1976, p. 821.

[7] Q.N. Liu, F. Song, S.H. Meng, and C.P. Jiang, Universal Biot number determining stress duration and susceptibility of ceramic cylinders to quenching, Philos. Mag. 90 (2010), p. 1726-1732.

[8] J.C. Jaeger, LI. On thermal stresses in circular cylinders, Philos. Mag. 36 (1945), p. 418-428.

[9] S.S. Manson, Behavior of materials under conditions of thermal stress, NACA TN 2933, (1953), p. 270.

[10] Y.F. Shao, Q.N. Liu, H.J. Tian, Z.K. Lin, X.H. Xu, and F. Song, Dimension limit for thermal shock failure, Philos. Mag. 94 (2014), p. 2647-2655.

[11] T.J. Lu and N.A. Fleck, The thermal shock resistance of solids, Acta Mater. 46 (1998), p. 47554768.

[12] F. Song, Q.N. Liu, S.H. Meng, and C.P. Jiang, A universal Biot number determining the susceptibility of ceramics to quenching, EPL (Europhys. Lett.) 87 (2009), p. 54001.

[13] H.G. Baron, Thermal shock and thermal fatigue, in Thermal Stresses, P.P. Benham and R. Hoyle, eds., Sir Isaac Pitman \& Sons Ltd., London, 1964, p. 182.

[14] S.S. Manson and T.J. Dolan, Thermal stress and low-cycle fatigue, J. Appl. Mech. 33 (1966), p. 957.

[15] P.F. Becher, Effect of water bath temperature on the thermal shock of $\mathrm{Al}_{2} \mathrm{O}_{3}$, J. Am. Ceram. Soc. 64 (1981), p. C17-C18. 
[16] J.P. Singh, Y. Tree, and D.P.H. Hasselman, Effect of bath and specimen temperature on the thermal stress resistance of brittle ceramics subjected to thermal quenching, J. Mater. Sci. 16 (1981), p. 2109-2118.

[17] Z.L. Zhou, F. Song, Y.F. Shao, S.H. Meng, C.P. Jiang, and J. Li, Characteristics of the surface heat transfer coefficient for $\mathrm{Al}_{2} \mathrm{O}_{3}$ ceramic in water quench, J. Eur. Ceram. Soc. 32 (2012), p. 3029-3034.

[18] P.J. Schneider, Conduction Heat Transfer, Addison-Wesley Publishing Company Inc, Cambridge, 1955, p. 255.

[19] B.A. Boley and J.H. Weiner, Theory of Thermal Stresses, Wiley, New York, 1960, p. 302.

[20] T.L. Bergman, A.S. Lavine, F.P. Incropera, and D.P. Dewitt, Fundamentals of Heat and Mass Transfer, Wiley, Hoboken, 2011, p. 987.

[21] D.L. Jiang, L.T. Li, S.X. Ouyang, and J.L. Shi, China Materials Engineering Canon, Chemical Industry Press, Beijing, 2006, p. 35.

[22] C.P. Jiang, X.F. Wu, J. Li, F. Song, Y.F. Shao, X.H. Xu, and P. Yan, A study of the mechanism of formation and numerical simulations of crack patterns in ceramics subjected to thermal shock, Acta Mater. 60 (2012), p. 4540-4550.

[23] J. Absi and J.C. Glandus, Improved method for severe thermal shocks testing of ceramics by water quenching, J. Eur. Ceram. Soc. 24 (2004), p. 2835-2838.

[24] H.M. Cheng, H.G. Wang, and T.L. Chen, Solution of heat conduction inverse problem for steel 45 during quenching, Acta Metall. Sinica 33 (1997), p. 467-472. 